\title{
The status of development of nanoparticle-based swine influenza vaccines: A review
}

Poudel $\mathrm{U}^{1 *}$, Pantha $\mathrm{S}^{2}$, Kaphle $\mathrm{K}^{3}$

*Corresponding author:

Mr. Uddab Poudel, B.V.Sc. \& A.H., 9th semester, Paklihawa Campus, Institute of Agriculture and Animal Science, Tribhuvan University, Siddharthanagar-1, Rupandehi, Nepal.

Email: poudeluddab15@gmail.com ORCID

\section{Information about the article:}

Received: August 5, 2019

Accepted: Oct. 1, 2019

Published online: Oct 27, 2019

\section{Cite this article:}

Poudel U, Pantha S, Kaphle K. The status of development of nanoparticle-based swine influenza vaccines: A review. Journal of Biomedical Sciences. 2019;6(1):6-11

\section{Publisher}

Nepal Health Research Society, Bahundhara -6, Gokarnesowor Municipality, Kathmandu, Nepal eISSN 2382-5545, ISSN 2676-1343 (Print)

(C) The Author(s). 2019

Content licensing: CC BY 4.0

\section{ABSTRACT \\ Background}

Swine are the most important meat animal, famous for white meat, which are prepared as ham, bacon, gammon, sausages and pork. Swine are valuable animals and they are physiologically, immunologically and anatomically similar to humans and their organ can be transplanted to the humans. Due to modernization, the cultural food restriction has lost in the people of urban communities and among the younger generations in Nepal. Gradually changing feeding habit of Nepalese has proven pork to be a useful addition to the food menu. Not only 8.7 lakhs swine in Nepal but the global pig population which occupy 769.05 million are suffering every day from new challenges and threats from very harmful pathogens and diseases like swine dysentery, coccidiosis, swine influenza, etc. Swine influenza is highly contagious rapidly spreading zoonotic viral disease of pigs characterized by febrile respiratory disease often complicated with secondary bacterial infections. Vaccines are only tool for prophylactic measures. There is big challenge for vaccine researchers, manufacturers and scientists for development of effective vaccine regarding swine influenza. Currently available flu vaccines are capable of homologous protection of virus but fail to induce cross protection against frequently evolving heterologous viruses. In this review, we discuss the status of novel nanoparticle-based approach of swine influenza virus vaccine development contributed significantly by Nepalese scientist and the future directions to control this economically important swine disease.

\section{Keywords}

Cross-protection, nanoparticles, pigs, swine influenza, vaccine, 


\section{Introduction}

Swine are the important and valuable food animals, globally popular for white meat [1]. Anatomically, physiologically, and immunologically; pigs are more similar to humans [2]. Swine are fast growing animals and provide maximum profit in short period of time, so swine farming is popular in Nepal. Due to cultural restrictions, consumption and farming is still not acceptable in Bhramin and Muslim communities in Nepal. In recent years, pig farming has got increased momentum in Nepal [3]. According to the year 2017 livestock statistics of Nepal, pig population in Nepal is around 8.7 lakhs [4]. Global pig population is about 769.05 million [5]. The health status of global pig population is challenged by existing and emerging viruses, bacteria, fungi and parasites infection day by day. For example, swine fever, Nipha virus encephalitis, porcine reproductive and respiratory syndrome (PRRS), swine influenza, porcine cysticercosis etc. are some of the economically important swine diseases. Due to the genetic diversity and the potential risk of human transmission swine influenza is an important zoonotic disease of swine with public health concern [6]. Swine influenza is an economically important disease of pigs with massive economic loss globally.

\section{Influenza $A$ and swine influenza virus}

Influenza A viruses (IAVs) are negative sense, single stranded RNA virus of Orthomyxoviridae family. The genome of the virus consists eight gene segments that encodes different viral proteins.

\begin{tabular}{ll}
\hline \multicolumn{2}{c}{ Table 1: Gene segment and encoded proteins } \\
\hline Viral genes & Protein(s) encoded \\
$1^{\text {st }}$ segment & Polymerase basic protein 2 (PB2) \\
$2^{\text {nd }}$ segment & Polymerase basic protein 1 (PB1) \\
$3^{\text {rd }}$ segment & Polymerase Acidic, (PA) \\
$4^{\text {th }}$ segment & Haemagglutinin (HA) \\
$5^{\text {th }}$ segment & Nucleoprotein (NP) \\
$6^{\text {th }}$ segment & Neuraminidase (NA) \\
$7^{\text {th }}$ segment & M1 and M2 proteins \\
$8^{\text {th }}$ segment & Non-structural protein-1 (NS-1) and NS-2 or \\
& Nuclear export protein (NEP) \\
\hline
\end{tabular}

IAVs have significant characteristics of enormous genetic variability led by antigenic drift and antigenic shift which create challenge for effective prevention and control. Antigenic drift is due to random mutation within individual genes and antigenic shift or reassortment occurs when two or more different influenza A viruses infect same cell and their RNA segments get exchanges resulting in novel reassortment viruses [7].

Swine influenza is a highly contagious zoonotic viral disease of pig characterized by respiratory disease producing clinical signs like coughing, sneezing, nasal discharge, and high temperature [8]. At present H1N1, H1N2 and H3N2 are the three subtypes of IAVs which cause infection in pigs [9].

\section{Prophylactic measure}

IAVs are the constant threat to humans and animals and vaccination is one of the most effective way to prevent and mitigate the disease. Currently available flu vaccines induce incomplete protection and only homologous protection but not heterologous protection against influenza viruses. Due to this, development of novel flu vaccine candidates is warranted to achieve greater efficacy against constantly evolving flu viruses [10].

Different types of Swine influenza vaccine have been developed which provide homologous protection only. In this review, we describe the nanoparticle-based approach of swine influenza vaccines development, carried forward by a Nepalese scientist at The Ohio State University (USA), which can induce heterologous protection and bear commercialization potential.

\section{PLGA nanoparticles-encapsulated conserved peptide} vaccine

PLGA (Polylactic-co-glycolic acid) is a non-toxic biodegradable and biocompatible polymer which are extensively used for drugs and vaccine delivery [11]. European Medicines Agency (EMA) and Food and Drug Administration (FDA) of the US have approved the PLGA for human use and applications. Even a soluble vaccine antigen can be entrapped in PLGA nanoparticles and elicit strong immune responses [12]. Entrapped conserved peptide antigen in PLGA nanoparticles are protected from enzymatic and ionic degradation [13]. Stalk domain of hemagglutinin (HA), matrix (M1 and M2) and nucleocapsids (NP) are highly conserved influenza viral protein [14]. The conserved proteins of influenza virus without potent adjuvant and proper delivery system are poor immunogenic.

Hiremath et al. (2016) developed PLGA entrapped conserved peptide vaccine. The vaccine contains Norovirus $\mathrm{P}$ particle containing swine influenza virus $\mathrm{m} 2 \mathrm{e}$ (extracellular domain of matrix protein 2) chimera and highly conserved two each of H1N1 peptides of pandemic 2009 and classical human influenza viruses were entrapped in nanoparticle, with or without Mycobacterium vaccae whole cell lysate as an adjuvant intranasally. The vaccine induced stronger epitope specific $\mathrm{T}$ - Cell responses, without boosting antibody responses which resulted in clearance of replicating virus from lungs of pigs. The $M$. vaccae adjuvant could not induce stronger antibody response indicating the need of alternative approaches.

\section{PLGA nanoparticles-delivered inactivated swine} influenza virus vaccine

PLGA nanoparticles also help in internalization, processing and presentation of the antigens by professional antigen presenting cells [15]. Antigen presenting cells easily uptake the PLGA nanoparticle 
which has size up to 500 nanometers [16]. PLGA nanoparticles protects the encapsulated antigen from the proteolytic degradation which occurs in the mucosal surface when administration through intranasal route and makes quick and easy uptake by the cells which are present in the mucosal surface of the respiratory tract. This type of nanoparticles have potential to develop strong mucosal immune response.

Dhakal et al. (2017) developed PLGA encapsulated inactivated swine influenza virus vaccine and tested in pigs in heterologous vaccine-challenge experiment. Pigs vaccinated with PLGA-delivered inactivated swine influenza virus vaccine have shown higher number of $\gamma \delta \mathrm{T}$ cells. The $\gamma \delta \mathrm{T}$ cells contributes for the induction of protective immune functions against influenza [17]. This vaccine activated greater numbers of cytotoxic $\mathrm{T}$-cell compared to control vaccine groups. The activated T-cells will produce INF- $\gamma$ cytokine which play important role in the clearance of influenza virus infected cells from respiratory tract [18]. For the clearance of intracellular pathogens, cell mediated immune response is important and the antigen presentation by major histocompatibility complex (MHC)-I mediate the cytotoxic T cells (CTL) responses [19]. PLGA-based swine influenza virus vaccine delivered by intranasal route did not induce effective humoral immune response but induced strong cytotoxic $\mathrm{T}$ cell response which resulted in protection of virulent heterologous influenza virus induced clinical diseases, reduced lungs pathology and cleared the virulent zoonotic heterologous virus from the lungs of pigs [20]. This technology has been patented and licensed to Aptimmune biologics Inc., St. Louis, MO, USA for potential commercialization in swine industry [21].

\section{Polyanhydride nanoparticles-delivered inactivated influenza virus vaccine}

Polyanhydrides are non-toxic, non-mutagenic polymer which are biodegradable and biocompatible having excellent sustained release properties [22]. Recently, Food and Drugs Administration (FDA) has approved polyanhydride based nanoparticles for antigen delivery in vaccines as they have self-adjuvant and physiochemical properties like hydrophilicity and crystallinity which help in proper immune induction [23]. Polyanhydride nanoparticles minimize the exposure of encapsulated antigens to moisture and provides better microenvironment for the antigens which are encapsulated [24]. Polyanhydride nanoparticles do not alter structural and biological activity of released vaccine antigens [2527]. Polyanhydride nanoparticles have pathogen mimicking properties which help to activate dendritic cells and help to enhance innate immune response $[28,29]$.

Dhakal et al. (2017) developed polyanhydride nanoparticle vaccine encapsulating whole inactivated swine influenza virus and analyzed the immunogenicity and efficacy of the vaccine against heterologous and virulent zoonotic swine influenza virus (H1N1) challenge in pigs. This vaccine increased virus specific cell mediated immune response but not the antibody responses and in turn reduced the viral fever and lungs pathology in pigs [30].

\section{Chitosan nanoparticles-delivered inactivated influenza virus vaccine}

Chitosan is a linear polysaccharide polymer which are synthesized by deacetylation of chitin which is abundantly found in nature [31]. Chitosan has been widely used for antigen delivery due to its biocompatibility, biodegradability, mucoadhesive, polycationic, selfadjuvant and immunomodulatory properties [32]. Chitosan nanoparticle do not need any organic solvents for preparation thus involve a simple and mild procedure for protecting sensitive biochemical agents including proteins and help in easy modulation of particles $[33,34]$.

Dhakal et al. (2018) developed mucoadhesive chitosan nanoparticles-delivered inactivated swine influenza virus vaccine using tripolyphosphate by ionotropic gelation technique. This chitosan-based nano vaccine administered through intranasal route elicited robust mucosal secretary (IgA) antibody response and virus-specific cell-mediated immunity in pigs resulting 100 times lower virus load in the respiratory tract of pigs compared to pigs vaccinated with inactivated soluble antigens [35]. This technology has been patented and being considered by the Ohio State University based startup company Nanicula for potential commercialization in swine industry [36].

\section{Liposomal nanoparticles-based conserved peptide vaccine}

Liposomes are the vesicular structure surrounding an aqueous core which are composed of one or more phospholipid bilayers [23]. For both hydrophilic and lipophilic entities liposomes represent an ideal nanocarrier [37]. Liposomes are used to enhance better encapsulation efficiency for the antigen and adjuvants, so they are ideal for antigen delivery [38]. The antigens are protected by liposomes from degradation facilitating slow release of antigen and enhance uptake of antigen by antigen presenting cells [39].

Dhakal et al. (2018) developed liposomal nanoparticlesbased highly conserved peptide influenza virus vaccine and tested in pigs administered intranasal together with monosodium urate crystal (MSU) adjuvant. MSU crystals are the safe and non-toxic agent to enhance peptide antigen immunogenicity. Intranasally administered liposomal nano vaccine with MSU adjuvants induced virus and peptide specific T-helper and memory cell populations, enhanced mucosal $\operatorname{Ig} \mathrm{A}$ response and reduced fever, virus load and pneumonic lesions in pigs after challenge with zoonotic and virulent IAV [40]. 
Future perspectives of nanoparticles-based swine influenza vaccine

Vaccines are the better choice for prophylactic measure against swine influenza virus infection in pigs. There are various influenza vaccine platforms based on nanoparticles being developed by a team including Nepalese scientist. Each nanoparticle-based vaccine formulation has its own advantages and disadvantages. An ideal vaccine against swine influenza virus must have characteristics of reducing difficulties which were encountered by other previous developed traditional vaccine. An ideal vaccine should be safe, cheap, easy to administer, biodegradable, biocompatible, non-toxic and should be able to prevent disease and virus shedding. An ideal vaccine should have not only homologous protection but also heterologous protection and should induce both humoral and cellular immune responses. A potent vaccine should induce effective herd immunity, preferably with single dose requirement and easy administration. Nanoparticle-based vaccine have the potential to induce both antibody as well as cell mediated immune responses in pigs depending on their chemical nature and provide protection against homologous and heterologous IAVs. With further research focused on developing balanced antibody and cell mediated immune responses, nanoparticle-based vaccines can serve as the better candidate swine influenza vaccine for global pig market.

\section{Conclusion}

In conclusion, nanoparticle-based Swine influenza vaccines are effective and better than traditional Swine Influenza vaccines, as it produces mucosal, humoral and cellular response and are capable of producing cell mediated and humoral immunity.

\section{Abbreviations}

Cytotoxic T-Cell (CTL), Influenza A Virus (IAV), Major Histocompatibility Complex (MHC), Monosodium Urate Crystals (MSU), Polylactic-Co-Glycolic Acid (PLGA)

\section{Authors' contribution}

UP composed the manuscript with the help of other authors. The manuscript was critically revised by all authors. Based on the feedbacks the manuscript was revised thoroughly. All the authors have agreed to the final content.

\section{Competing interests}

The authors declare no conflicts of interest.

\section{Acknowledgments}

We are thankful to Dr. Santosh Dhakal, a Postdoctoral Fellow at Johns Hopkins Bloomberg School of Public Health, Baltimore, MD and Dr. Srijan Bastola for their special help and support.

\section{Publisher's Note}

NHRS remains neutral with regard to jurisdictional claims in published maps and institutional affiliations.

The publisher shall not be legally responsible for any types of loss, actions, claims, proceedings, demand or costs or damages whatsoever or howsoever caused arising directly or indirectly in connection with or arising out of the use of this material.

\section{Author information}

${ }^{1}$ Mr. Uddab Poudel, B.V.Sc. \& A.H., 9th semester, Paklihawa Campus, Institute of Agriculture and Animal Science, Tribhuvan University, Siddharthanagar-1, Rupandehi, Nepal

${ }^{2}$ Saurav Pantha, B.V.Sc. \& A.H., 9th semester, Paklihawa Campus, Institute of Agriculture and Animal Science, Tribhuvan University, Siddharthanagar-1, Rupandehi, Nepal ${ }^{3}$ Dr. Krishna Kaphle, Department of Theriogenology, Paklihawa Campus, Institute of Agriculture and Animal Science, Tribhuvan University, Siddharthanagar-1, Rupandehi, Nepal

\section{References}

1. Keeton JT, Dikeman ME. 'Red' and 'white' meats - terms that lead to confusion. Animal Frontiers. 2017;7(4): 29-33. DOI: https://doi.org/10.2527/af.2017.0440

2. Pabst R, Binns RM. The immune system of the respiratory tract in pigs. Veterinary immunology and immunopathology, 1994;43(1-3):151-6. DOI: https://doi.org/10.1016/01652427(94)90131-7

3. Pig Farming in Nepal. Accessed on 10.10.19 from the http://www.ceapred.org.np/userfiles/image/Knowl edge_Bank/Analysis\%20of\%20Pig\%20and\%20Po rk\%20Market\%20System\%20in\%20Nepa.pdf

4. Livestock Statistics Of Nepal. 2017, July. Accessed on 10.10.19 from the url "http:/www.mold.gov.np/downloadfile/Tathaynka \%20Pustika\%20final\%20for\%20print_151013286 2.pdf"

5. No. Of Pigs Worldwide 2018 by leading Country, Accessed on 10.10.19 from the url "https://www.statista.com/statistics/263964/numbe r-of-pigs-in-selected-countries/"

6. Gray GC, McCarthy T, Capuano AW, Setterquist SF, Olsen CW, Alavanja MC, Lynch CF. Swine workers and swine influenza virus infections. Emerging infectious diseases, 2007;13(12):1871. DOI: $\underline{\text { https://doi.org/10.3201/eid1312.061323 }}$

7. Treanor J. Influenza vaccine-outmaneuvering antigenic shift and drift. New England Journal of Medicine, 2004;350(3):218-20. DOI: https://dx.doi.org/10.1056/NEJMp038238 
8. Chakrabarti AA Textbook of Preventive Veterinary Medicine. New Delhi: Kalyani publishers, 2012.

9. Taubenberger JK, Kash JC. Influenza virus evolution, host adaptation, and pandemic formation. Cell host \& microbe, 2010;7(6):440-51. DOI: https://doi.org/10.1016/j.chom.2010.05.009

10. Zinsstag J, Schelling E, Roth F, Bonfoh B, De Savigny D, Tanner M. Human benefits of animal interventions for zoonosis control. Emerging infectious diseases, 2007;13(4): 527.

DOI: https://doi.org/10.3201/eid1304.060381

11. Danhier F, Ansorena E, Silva JM, Coco R, Le Breton A, Préat V. PLGA-based nanoparticles: an overview of biomedical applications. Journal of controlled release, 2012;161(2):505-22.

DOI: https://doi.org/10.1016/j.jconrel.2012.01.043

12. McNeil SE. Nanotechnology for the biologist. Journal of leukocyte biology, 2005;78(3):585-94. DOI: https://doi.org/10.1189/jlb.0205074

13. Getts DR, Shea LD, Miller SD, King NJ. Harnessing nanoparticles for immune modulation. Trends in immunology, 2015;36(7):419-27. DOI: https://doi.org/10.1016/j.it.2016.08.003

14. Hiremath J, Kang KI, Xia M, Elaish M, Binjawadagi B, Ouyang K, Lee CW. Entrapment of H1N1 influenza virus derived conserved peptides in PLGA nanoparticles enhances $\mathrm{T}$ cell response and vaccine efficacy in pigs. PLoS One, 2016;11(4):e0151922.

DOI: https://doi.org/10.1371/journal.pone.0151922

15. Woodrow KA, Bennett KM, Lo DD. Mucosal vaccine design and delivery. Annual review of biomedical engineering, 2012;14, 17-46.

DOI: $\quad$ https://doi.org/10.1146/annurev-bioeng071811-150054

16. Foged C, Brodin B, Frokjaer S, Sundblad A. Particle size and surface charge affect particle uptake by human dendritic cells in an in vitro model. International journal of pharmaceutics, 2005;298(2):315-22.

DOI:

https://doi.org/10.1016/j.ijpharm.2005.03.035

17. Welsh RM, Lin MY, Lohman BL, Varga SM, Zarozinski CC Selin LK. $\alpha \beta$ and $\gamma \delta$ T-cell networks and their roles in natural resistance to viral infections. Immunological reviews, 1997; 159(1):79-93.

DOI: $\quad$ https://doi.org/10.1111/j.1600065X.1997.tb01008.x

18. Bot A, Bot S, Bona CA. Protective role of gamma interferon during the recall response to influenza virus. Journal of virology, 1998; 72(8):6637-45.

19. Makadia HK, Siegel SJ. Poly lactic-co-glycolic acid (PLGA) as biodegradable controlled drug delivery carrier. Polymers, 2011; 3(3):1377-97.
DOI: https://doi.org/10.3390/polym3031377

20. Dhakal S, Hiremath J, Bondra K, Lakshmanappa YS, Shyu DL, Ouyang K, Krakowka S. Biodegradable nanoparticle delivery of inactivated swine influenza virus vaccine provides heterologous cell-mediated immune response in pigs. Journal of Controlled Release, 2017; 247, 194-205.

DOI: https://doi.org/10.1016/j.jconrel.2016.12.039

21. Nanoparticle based vaccine strategy against swine influenza virus. Retrieved From "https:// patents.google.com/patent/US20180243228A1/en"

22. Gómez S, Gamazo C, San Roman, B, Ferrer M, Sanz ML, Irache JM. Gantrez® AN nanoparticles as an adjuvant for oral immunotherapy with allergens. Vaccine, 2007;25(29):5263-71.

DOI:

https://doi.org/10.1016/j.vaccine.2007.05.020

23. Karandikar S, Mirani A, Waybhase V, Patravale VB, Patankar S. Nanovaccines for oral deliveryformulation strategies and challenges. 2017 In Nanostructures for Oral Medicine (pp. 263-293). Elsevier.

DOI: https://doi.org/10.1016/B978-0-323-47720$\underline{8.00011-0}$

24. Determan AS, Trewyn BG, Lin VSY, NilsenHamilton M, Narasimhan B. Encapsulation, stabilization, and release of BSA-FITC from polyanhydride microspheres. Journal of controlled release, 2004;100(1): 97-109.

DOI: https://doi.org/10.1016/j.jconrel.2004.08.006

25. Ross KA, Loyd $\mathrm{H}, \mathrm{Wu} \mathrm{W}$, Huntimer L, Wannemuehler MJ, Carpenter S, Narasimhan B. Structural and antigenic stability of $\mathrm{H} 5 \mathrm{~N} 1$ hemagglutinin trimer upon release from polyanhydride nanoparticles. Journal of Biomedical Materials Research Part A, 2014;102(11):4161-8.

DOI: https://doi.org/10.1002/jbm.a.35086

26. Vela Ramirez, JE, Roychoudhury R, Habte HH, Cho, MW, Pohl NLB, Narasimhan B, Carbohydrate-functionalized nanovaccines preserve HIV-1 antigen stability and activate antigen presenting cells. Journal of Biomaterials Science, Polymer Edition,2014; 25(13):1387-406. DOI: https://doi.org/10.1080/09205063.2014.940243

27. Haughney SL, Petersen LK, Schoofs AD, RamerTait, AE, King JD. Retention of structure, antigenicity, and biological function of pneumococcal surface protein A (PspA) released from polyanhydride nanoparticles. Acta biomaterialia, 2013; 9(9):8262-71.

DOI: $\underline{\text { https://doi.org/10.1016/j.actbio.2013.06.006 }}$

28. Torres MP, Determan AS, Anderson GL, Mallapragada SK, Narasimhan, B. Amphiphilic 
polyanhydrides for protein stabilization and release. Biomaterials, 2007;28(1): 108-16.

DOI:

https://doi.org/10.1016/j.biomaterials.2006.08.047

29. Petersen LK, Ramer-Tait, AE, Broderick SR, Kong CS, Ulery BD, Rajan K, Narasimhan B. Activation of innate immune responses in a pathogen-mimicking manner by amphiphilic polyanhydride nanoparticle adjuvants. Biomaterials, 2011; 32(28):6815-22.

DOI:

https://doi.org/10.1016/j.biomaterials.2011.05.063

30. Dhakal S, Goodman J, Bondra K, Lakshmanappa YS, Hiremath J, Shyu DL. Polyanhydride nanovaccine against swine influenza virus in pigs. Vaccine,2017;35(8)1124-31.

DOI:

https://doi.org/10.1016/j.vaccine.2017.01.019

31. Illum L, Jabbal-Gill I, Hinchcliffe M, Fisher AN, Davis SS. Chitosan as a novel nasal delivery system for vaccines. Advanced drug delivery reviews, 2001;51(1-3):81-96.

DOI: $\quad$ https://doi.org/10.1016/S0169409X(01)00171-5

32. Wang JJ, Zeng ZW, Xiao RZ, Xie T, Zhou GL. Recent advances of chitosan nanoparticles as drug carriers. International journal of nanomedicine, 6 , 765.

DOI: https://doi.org/10.2147/IJN.S17296

33. Peniche H, Peniche C. Chitosan nanoparticles: a contribution to nanomedicine. Polymer International, 2011;60(6):883-9.

DOI: https://doi.org/10.1002/pi.3056

34. Rampino A, Borgogna M, Blasi P, Bellich B, Cesàro A. Chitosan nanoparticles: preparation, size evolution and stability. International journal of pharmaceutics, 2013; 455(1-2):219-28.

DOI:

https://doi.org/10.1016/j.ijpharm.2013.07.034

35. Dhakal S, Renu S, Ghimire S, Lakshmanappa YS, Hogshead BT, Feliciano-Ruiz N. Mucosal immunity and protective efficacy of intranasal inactivated influenza vaccine is improved by chitosan nanoparticle delivery in pigs. Frontiers in immunology, 2018;9, 934

DOI: https://doi.org/10.3389/fimmu.2018.00934

36. Nanicula. (2019). Accessed on 10.10.19 from the url "https:// nanicula.wixsite.com/naniculavaccines"

37. Torchilin, VP. Recent advances with liposomes as pharmaceutical carriers. Nature reviews Drug discovery, 2005;4(2):145.

DOI: https://doi.org/10.1038/nrd1632

38. Henriksen-Lacey, M., Korsholm, K. S., Andersen, P Perrie Y, Christensen D. Liposomal vaccine delivery systems. Expert opinion on drug delivery,
2011;8(4):505-19.

DOI: https://doi.org/10.1517/17425247.2011.558081

39. Bernasconi V, Norling K, Bally M, Höök F, Lycke NY. Mucosal vaccine development based on liposome technology. Journal of immunology research, 2016.

DOI: http://dx.doi.org/10.1155/2016/5482087

40. Dhakal S, Cheng X, Salcido J, Renu S, Bondra K, Lakshmanappa, YS, Krakowka, S. (2018). Liposomal nanoparticle-based conserved peptide influenza vaccine and monosodium urate crystal adjuvant elicit protective immune response in pigs. International journal of nanomedicine, 13, 6699. DOI: https://doi.org/10.2147/IJN.S178809 